\title{
e-interview
}

\section{Fuad Antun}

Fuad Antun practises in Lebanon and is President of the Scientific Council for the Arab Board of Psychiatric Training. He trained at the University and the Medical Research Council Brain Metabolism Unit in Edinburgh. His interests include clinical adult and adolescent psychiatry, biological psychiatry, and mental health training in primary care.

If you were not a psychiatrist, what would you do?

I would have gone into cinematography preferably as a director.

What has been the greatest impact of your profession on you personally? It has allowed me to pursue my interest in the impact of genetics on behaviour.

\section{Do you feel stigmatised}

by your profession?

I do not feel stigmatised personally but sometimes disturbed by the public's misconception of mental health issues. The media are in some ways responsible for propagating certain misconceptions.

What are your interests outside of work?

I am a jazz enthusiast, l enjoy good films and documentaries and I'm particularly interested in archaeology.

What job gave you the most useful training experience?

Working at the Royal Edinburgh Hospital with an eclectic clinical approach and the basic neuroscience bench research that I did for my PhD at the MRC Unit.

Which publication has influenced you most?

There is no single publication, but I have been influenced by the scientific literature on the effect of hallucinogens on the limbic system.

How has the political environmental influenced your work?

Soon after I returned to Lebanon in 1972 to work at the American University of Beirut as Chairman of the Psychiatry Department, armed conflict began and I had to cope with the security situation, administration, clinical and teaching work. Many physicians and

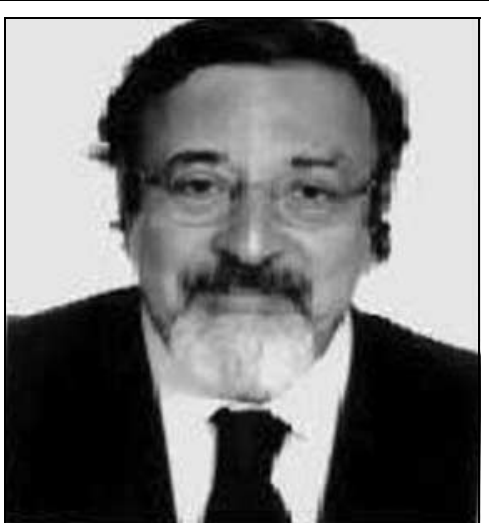

psychiatrists left the country at this time. I gained a great sense of achievement from learning to manage numerous responsibilities and how to cope with work stress.

What part of your work gives you the most satisfaction? Patient care and participating in international conferences.

\section{What do you least enjoy?}

As advisor to the Ministry of Health in Lebanon, I have to deal with bureaucrats and politicians who have little understanding of mental health needs and as a result are slow to introduce legislation.

\section{What is the most promising} opportunity facing the profession? The inter-disciplinary approach in linking heredity and neuroscience in order to better understand behaviour.

\section{What is the greatest threat?}

Excessive specialisation in mental health which can blur the public understanding of psychiatry and decrease funding support, particularly if the specialty distances itself from the medical field.

\section{What single change would} substantially improve quality of care? Customising care to the needs of the individual community and country.

What conflict of interest do you encounter most often?

The well-being of patients $v$. the demands of society and reaching a balance between over-concern and abandonment of responsibility for the patient. This can present the psychiatrist with a challenging dilemma at times.

What is the role of the psychiatrist in countries emerging from conflict? To deal with psychosocial problems and ensure continuing care for those patients already receiving treatment. Sometimes a psychiatrist has to be involved with the media and socio-political issues.

What is the most important advice you could offer to a new trainee? Psychiatry is a psychosocial discipline. However, the concept of mind integrated with body should always guide psychiatric practice.

What are the main ethical problems that psychiatrists will face in the future?

Changing social attitudes, how to increase tolerance and understanding of mental health issues, and tailoring mental health legislation.

Do you think psychiatry is brainless or mindless?

Psychiatrists should always recognise the fact that the brain is the basis of behaviour and determines the interaction of man and environment.

What is the role of the psychiatrist in rebuilding healthcare systems? The behavioural sciences are an integral part of healthcare systems and consequently the psychiatrist should have an active role in their development.

What single change to mental health legislation would you like to see? Legislation that allows flexibility in the exercise of clinical judgement.

What single area of psychiatric practice is most in need of development? Continuity of care with a team approach.

What single area of psychiatric research should be given priority? I am biased in favour of biological research! Dominic Fannon doi: 10.1192/pb.bp.107.017665 